\title{
Extracorporeal Partial Nephrectomy with Orthotopic Autotransplantation under Pharmaco-Cold Ischaemia for Cancer of a Single Kidney: A Case Report
}

\author{
Tatiana Baitman $^{a} \quad$ Irina Miroshkina $^{a} \quad$ Alexander Gritskevich $^{a}$ \\ Alexander Teplov ${ }^{a} \quad$ Andrey Zotikov $^{b} \quad$ Alexander Kochetov ${ }^{c}$ \\ Valentina Demidovad Andrey Chupin ${ }^{b}$ Yulia Stepanova ${ }^{\mathrm{e}}$ \\ Wolfgang Schima ${ }^{f}$ Grigory Karmazanovskyg
}

\begin{abstract}
aDepartment of Urology, A.V. Vishnevsky National Medical Research Center of Surgery of the Ministry of Healthcare of the Russian Federation, Moscow, Russia; ${ }^{b}$ Department of Vascular Surgery, A.V. Vishnevsky National Medical Research Center of Surgery of the Ministry of Healthcare of the Russian Federation, Moscow, Russia; The Urology Center of A.A. Vishnevsky III Central Military Clinical Hospital, Moscow, Russia; dThe Department of Laboratory Diagnostics, A.V. Vishnevsky National Medical Research Center of Surgery of the Ministry of Healthcare of the Russian Federation, Moscow, Russia; ${ }^{\text {eThe Department }}$ of Ultrasound Diagnostics, A.V. Vishnevsky National Medical Research Center of Surgery of the Ministry of Healthcare of the Russian Federation, Moscow, Russia; ${ }^{f}$ The Department of Diagnostic and Interventional Radiology, Göttlicher Heiland Krankenhaus, Barmherzige Schwestern Krankenhaus, and St. Josef Krankenhaus, Vinzenzgruppe, Vienna, Austria; 9The Department of Radiology, A.V. Vishnevsky National Medical Research Center of Surgery of the Ministry of Healthcare of the Russian Federation, Moscow, Russia
\end{abstract}

\section{Keywords}

Renal cell carcinoma - Inferior vena cava tumour thrombosis - Tumour of a single kidney . Nephron-sparing surgery · Contrast-enhanced multiple detector computed tomography

\begin{abstract}
Up to $10 \%$ of patients with renal cell carcinoma (RCC) have locally advanced disease with venous tumour thrombosis involving the inferior vena cava (IVC). $30-50 \%$ of them present with synchronous metastatic disease. Surgical treatment remains the only potentially radical method for patients suffering from RCC and IVC tumour thrombosis without distant metastases. Five-year cancer-specific survival for such patients is $40-60 \%$. The role of surgery in the treatment of RCC is significant, even if only cytoreductive operation is possible. Nephron-sparing surgery (NSS) is reasonably preferable for patients suffering from single kidney RCC, but it is not always radical enough. Extracorporeal approach allows to perform a radical dissection of
\end{abstract}


the tumour in special complicated cases, but it is seldom used because of technical difficulties. We present a case of successful NSS by extracorporeal approach in our modification for RCC with IVC tumour thrombosis.

\section{Introduction}

Renal cell carcinoma (RCC) takes the 10th place in the cancer morbidity pattern for both sexes. There is a significant $26 \%$ increase in RCC incidence over the last 10 years [1]. Formation of venous tumour thrombus spreading into the renal vein and inferior vena cava (IVC) is typical for RCC, making up to $25 \%$ of cases [2]. The thrombi can reach the right atrium and ventricle and even the pulmonary artery [3]. The combination of RCC and IVC tumour thrombus is a complex high-risk surgical problem.

\section{Case Report}

A 65-year-old man presented with dull low-intensity pain in the right lumbar region. The patient had a left-sided nephrectomy for a gunshot wound 20 years before. A contrastenhanced multiple detector computed tomography scan showed a large multinodular transmurally growing tumour of the upper half of the right kidney, sized $101 \times 75 \times 95 \mathrm{~mm}$, spreading to the renal sinus. A non-occlusive vascularized tumour thrombus was visualized in the right renal vein and IVC. The thrombus component located in the IVC was $62 \mathrm{~mm}$ in length, the thrombus head was found on the border of the liver segment of IVC. There was also a single metastasis in the right adrenal gland, sized $25 \times 20 \mathrm{~mm}$ (Fig. 1). Cancer of the solitary right kidney, stage IV, cT3bN0M1 [ADR], complicated with cava-renal intraluminal invasion was diagnosed.

The preoperative level of urea was $5.18 \mathrm{mmol} / \mathrm{L}$, creatinine $122 \mu \mathrm{mol} / \mathrm{L}$, and glomerular filtration rate was $66 \mathrm{~mL} / \mathrm{min}$.

Subsequently, extracorporeal partial nephrectomy (ECPN) of the solitary right kidney with orthotopic vascular replantation under pharmaco-cold ischaemia, thrombectomy of the IVC, right-sided adrenalectomy, lymphadenectomy, preventive creation of an arteriovenous fistula on the right radial artery were performed within the Urological Department of the A.V. Vishnevsky National Medical Research Center of Surgery.

Intraoperatively, a tumour node measuring $101 \times 75 \times 95 \mathrm{~mm}$ was found on the lateral surface of the upper part of the kidney. One-third of the node was located extrarenally. A tumour thrombus was palpated in the renal vein. The intraoperative ultrasound (US) showed inhomogeneous floating thrombotic masses along the entire length of the renal vein. The length of the tumour thrombus was $67 \mathrm{~mm}$, the head of the thrombus located in the IVC, almost spreading to the hepatic segment of the IVC. There was no retrograde apposition thrombus present.

The ureter was mobilized without transection. The supra- and infrarenal segments of aorta, IVC, and right renal artery and vein were mobilized. We also formed a channel under the IVC to conduct the right renal artery during the reimplantation. Systemic heparinization at a dose of 2,500 units was performed. The renal artery was clamped and crossed near its origin. The arterial stump was ligated and stitched. The IVC was clamped below the hepatic and right renal veins. The IVC was resected along the origin line of the right renal vein with a hood pattern from the IVC wall in the distal direction. The tumour thrombus was pulled out

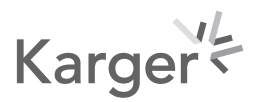




\section{Case Reports in Oncology}

\begin{tabular}{l|l}
\hline Case Rep Oncol 2020;13:1202-1208 \\
\hline DOI: 10.1159/000510404 & $\begin{array}{l}\text { @ 2020 The Author(s). Published by S. Karger AG, Basel } \\
\text { www.karger.com/cro }\end{array}$ \\
\hline
\end{tabular}

Baitman et al.: Extracorporeal Partial Nephrectomy for Cancer of a Single Kidney

Fig. 1. Contrast-enhanced multiple detector computed tomography. A Axial plane. B Coronal plane. 1, multinodular tumour; 2, non-occlusive vascularized tumour thrombus in the right renal vein and IVC.
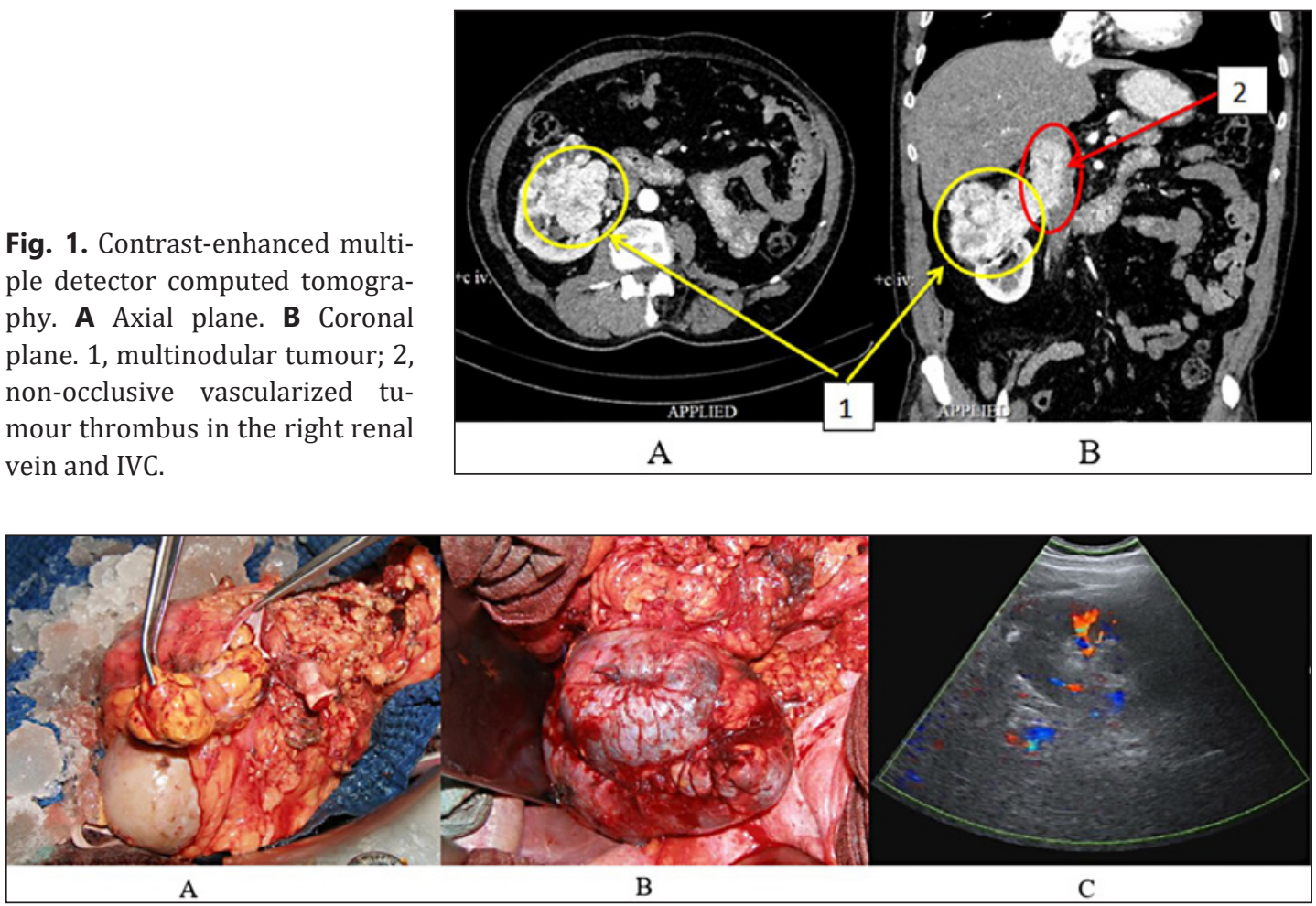

Fig. 2. Intraoperative photographs. A The mobilized kidney removed into the tray with ice crumbs. B The kidney after the re-start of blood flow. C Ultrasound image of the kidney after the start of blood flow.

of the vein. Vascular clamps were taken off the IVC immediately after a clamp was applied on the IVC defect. The time of warm ischaemia was $12 \mathrm{~min}$.

The mobilized kidney was placed on the abdominal wall into the tray filled with ice crumbs. From that point and during the whole ischaemia time the kidney was being conserved with ice crumbs wrapping, and perfusion of refrigerated $\left(+2-4^{\circ} \mathrm{C}\right)$ pharmacoplegic solution was performed via the cannula inserted into the renal artery (Fig. 2A). The perfusion pressure of $100 \mathrm{~mm} \mathrm{Hg}$ was achieved with a pneumatic cuff with a pressure gauge.

The renal tumour was removed without any violation to pelvicalyceal system. The vessels of the resected area were sutured. The intraluminal tumour mass was extracted from the dissected renal vein to the level of segmental veins. The intraparenchymal part of the intraluminal segmental tumour masses was excised. The kidney parenchyma was sutured and additionally treated with haemostatic foam. We created the cava-renal vascular anastomosis end-to-side, implanting the renal vein into the IVC defect. Aortotomy was carried out infrarenally with a punch, and the renal artery was implanted there end-to-side. The vascular anastomoses were tested. Kidney perfusion looked acceptable (Fig. 2B), and US testing confirmed that (Fig. 2C). The time of pharmaco-cold ischaemia was $218 \mathrm{~min}$.

The postoperative period was characterized by the development of acute kidney injury stage F on RIFLE criteria, which required 2 haemodiafiltration sessions. Antibacterial, infusion, blood transfusion, and anticoagulant therapy were carried out postoperatively. Diuresis was restored on the 6th day after surgery. The patient was discharged from the hospital in satisfactory condition on the 12 th postoperative day.

According to histopathology, it was a clear-cell RCC of the solitary right kidney, grade 3, characterized by ingrowth into the perinephric tissue, venous invasion and the formation of 


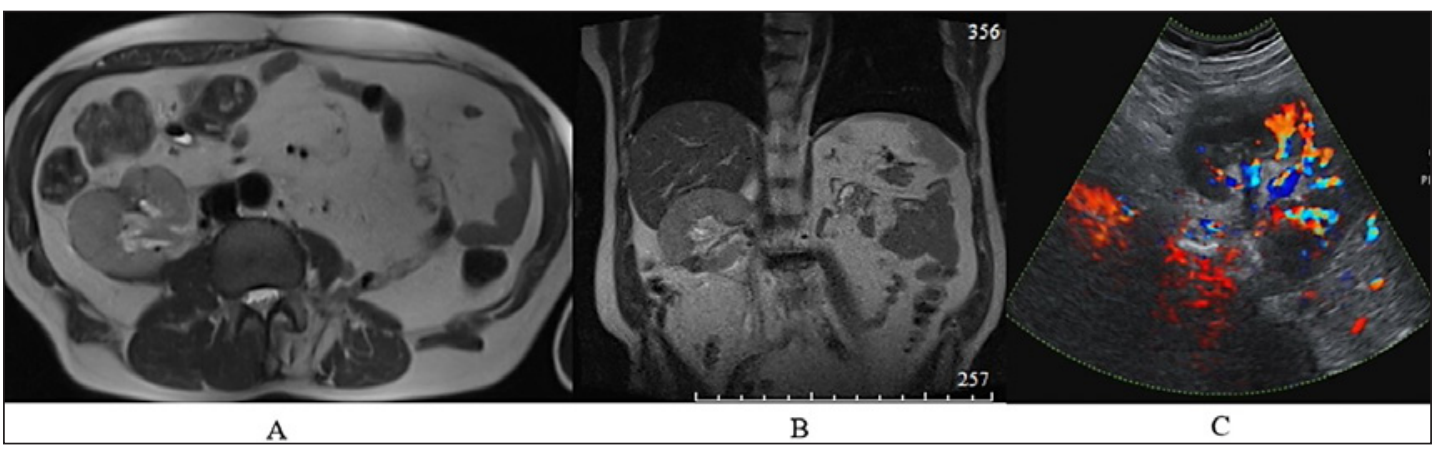

Fig. 3. Sixteen months after the operation: magnetic resonance imaging of the kidney (A axial plane; B coronal plane) demonstrates the post-surgical defect of the kidney, but no recurrent tumour. C Ultrasound image of the kidney proves adequate blood flow.

Table 1. Evaluation of the kidney function before and after surgery

\begin{tabular}{|c|c|c|c|c|}
\hline \multirow{2}{*}{$\begin{array}{l}\text { Biochemical parameters of the excretion } \\
\text { function }\end{array}$} & \multicolumn{4}{|c|}{ Longitudinal evolution of kidney function } \\
\hline & $\begin{array}{l}\text { Before } \\
\text { surgery }\end{array}$ & $\begin{array}{l}\text { 1st day } \\
\text { after surgery }\end{array}$ & $\begin{array}{l}3 \text { months } \\
\text { after surgery }\end{array}$ & $\begin{array}{l}16 \text { months } \\
\text { after surgery }\end{array}$ \\
\hline Urea, mmol/L & 5.18 & 9.2 & 12.4 & 10.3 \\
\hline Creatinine, $\mu \mathrm{mol} / \mathrm{L}$ & 122 & 312 & 183 & 189 \\
\hline Glomerular filtration rate, $\mathrm{mL} / \mathrm{min}$ & 66 & 26 & 44 & 43 \\
\hline
\end{tabular}

a tumour thrombus in the IVC. The right adrenal gland metastasis was also clear-cell RCC. There were no tumour metastases in the 10 regional lymphatic nodes.

On follow-up examination 16 months after the surgery there were no signs of local tumour recurrence and metastases to parenchymal organs according to magnetic resonance imaging of the abdominal cavity and pelvis (Fig. 3A, B). According to US (Fig. 3C) and laboratory data (Table 1), the kidney function is satisfactory at follow-up, and there is no need in the renal replacement therapy (RRT).

\section{Discussion}

The treatment of patients who suffer from RCC complicated by tumour thrombosis is still debatable. Nowadays, the gold standard for it is radical nephrectomy (RN) with thrombectomy [2].

The research of Gayed et al. [4] at the University of Texas Southwestern Medical Center is probably the largest one in the field of RN and thrombectomy in patients with RCC. The study included 146 patients who underwent RN with venous thrombectomy between 1998 and 2012. The rate of complications was 77 (53\%), high-grade complications occurred in 15 (10\%) of cases. Thirty-day postoperative mortality was $2.7 \%$. Five-year overall survival (OS) and 5-year cancer-specific survival were 51 and 40\%, respectively. Metastases were the only independent predictor of cancer-specific survival and OS in all patients [5].

Nephron-sparing surgery (NSS), which is more preferable for preserving of the renal function, may not always be oncologically radical, and therefore it is partly an experimental 
technique now. However, resection is recognized as the standard of treatment for patients with RCC of a single kidney [2, 4]. NSS allows maintaining acceptable kidney function and avoiding the constant need for RRT. NSS equally has advantages over kidney transplantation, considering the shortage of donor organs worldwide. Moreover, it is a more cost-effective method, not requiring any delay or immunosuppressive therapy known for its adverse effects [6-15].

One of the largest studies of NSS for RCC spreading to the IVC includes 140 patients who underwent treatment at Emory University, Atlanta, from 2005 to 2016. Postoperative complications were noted in 39 (28\%) cases. Ninety-day mortality was 7\%: 4 patients died due to postoperative complications, and 6 fatal outcomes were associated with the progression of RCC. RCC recurrence was noted in $25 \%$ of cases. Median OS of the entire cohort was 43.8 months (5-year OS: 43\%), and 73.6 months (5-year OS: 59\%) for those without metastatic disease. RRT was required in $2(1 \%)$ cases [16].

In some cases, when "in situ" renal resection is not possible (multiple, large, or centrally located tumours), authors resorted to performing ECPN with ortho- or heterotopic autotransplantation of the resected kidney $[12,17]$. Currently, the experience with such operations is not great, but their results are satisfactory [12,14, 16-19]. Anyhow, we could not find cases of ECPN with orthotopic replantation under pharmaco-cold ischaemia for RCC complicated by IVC tumour thrombosis in single kidney in the literature.

\section{Conclusion}

ECPN of a solitary or the only functioning kidney is a technically difficult intervention, requiring not only precise surgical technique, but also a specific approach to examination and postoperative conservative therapy. This operation should be performed in a selected group of patients in a highly specialized multidisciplinary hospital.

\section{Statement of Ethics}

The patient gave his written informed consent to publish this case (including publication of images).

\section{Conflict of Interest Statement}

There is no conflict of interest.

\section{Funding Sources}

The case report was written without any funding.

\section{Author Contributions}

Tatiana Baitman - acquisition, analysis, and interpretation of data for the work; drafting the work; final approval of the version to be published; agreement to be accountable for all aspects of the work. Irina Miroshkina - acquisition, analysis, and interpretation of data for the 
work; drafting the work; final approval of the version to be published; agreement to be accountable for all aspects of the work. Alexander Gritskevich - contributions to the conception and design of the work; revising the work; final approval of the version to be published; agreement to be accountable for all aspects of the work. Alexander Teplov - contributions to the conception and design of the work; revising the work; final approval of the version to be published; agreement to be accountable for all aspects of the work. Andrey Zotikov - contributions to the conception and design of the work; revising the work; final approval of the version to be published; agreement to be accountable for all aspects of the work. Alexander Kochetov - contributions to the conception and design of the work; revising the work; final approval of the version to be published; agreement to be accountable for all aspects of the work. Valentina Demidova - contributions to the conception and design of the work; revising the work; final approval of the version to be published; agreement to be accountable for all aspects of the work. Andrey Chupin - contributions to the conception and design of the work; revising the work; final approval of the version to be published; agreement to be accountable for all aspects of the work. Yulia Stepanova - contributions to the conception and design of the work; revising the work; final approval of the version to be published; agreement to be accountable for all aspects of the work. Wolfgang Schima - contributions to the conception and design of the work; revising the work; final approval of the version to be published; agreement to be accountable for all aspects of the work. Grigory Karmazanovsky - contributions to the conception and design of the work; revising the work; final approval of the version to be published; agreement to be accountable for all aspects of the work.

\section{References}

1 Caprin AD, Starinskiy VV, Petrova GV (eds). Malignant neoplasms in Russia in 2018 (morbidity and mortality). Moscow: Moscow P.A. Gertsen Research Institute of Oncology; 2019. pp. 250. https://glavonco.ru/cancer register.

2 Ljungberg B, Albiges L, Abu-Ghanem Y, Bensalah K, Dabestani S, Fernández-Pello S, et al. EAU guidelines on renal cell carcinoma: 2019 update. Eur Urol. 2019;67:913-24. https://www.europeanurology.com/article/ S0302-2838(19)30152-6/fulltext.

3 Davydov MI, Matveev VB, Volkova MI, Feoktistov PI, Kuznetsov KP, Nekhaev IV, et al. Surgical treatment of Renal Cell Carcinoma (RCC) with level III-IV tumour venous thrombosis. Cancer Urology. 2016;12(4):21-34.

4 Gayed BA, Youssef R, Darwish O, Kapur P, Bagrodia A, Brugarolas J, et al. Multidisciplinary surgical approach to the management of patients with renal cell carcinoma with venous tumour thrombus: 15-year experience and lessons learned. BMC Urol. 2016;16(1):43.

5 Mickisch G, Garin A, van Poppel H, de Prijck L, Sylvester R. Radical nephrectomy plus interferon-alfa-based immunotherapy compared with interferon alfa alone in metastatic renal-cell carcinoma: a randomised trial. Lancet. 2001;358(9286):966-70.

6 McKiernan J, Simmons R, Katz J, Russo P. Natural history of chronic renal insufficiency after partial and radical nephrectomy. Urology. 2002;59:816.

7 Rocco M, Frankenfield DL, Hopson SK, McClellan WM. Relationship between clinical performance measures and outcomes among patients receiving long-term hemodialysis. Ann Intern Med. 2006;145:512.

8 Lin SJ. The association between length of post-kidney transplant hospitalization and long-term graft and recipient survival. Clin Transplant. 2006;20:245.

9 Foley R. Clinical epidemiology of cardiovascular disease in chronic kidney disease. J Ren Care. 2010;36:4-8.

10 Agochukwu NQ, Metwalli AR, Kutikov A, Pinto PA, Linehan WM, Bratslavsky G. Economic burden of repeat renal surgery on solitary kidney - do the ends justify the means? A cost analysis. J Urol. 2012;188:1695-700.

11 McAdams-DeMarco MA, King EA, Luo X, Haugen C, DiBrito S, Shaffer A, et al. Frailty, length of stay, and mortality in kidney transplant recipients: a National registry and prospective cohort study. Ann Surg. 2017;266:108490.

12 Gritskevich AA, Miroshkina IV, Piyanikin SS, Adyrkhayev ZA, Stepanova YA, Zotikov AE, et al. Extracorporeal partial nephrectomy under pharmaco-cold ischemia for renal cell carcinoma. Khirurgiya. Zhurnal im. N.I. Pirogova. 2017;1:42-7.

13 Tsampalieros A, Knoll GA, Dixon S, English S, Manuel D, Walraven CV, et al. Case mix, patterns of care, and inpatient outcomes among Ontario kidney transplant centers: a population-based study. Can J Kidney Health Dis. 2018;17(5):1-16.

14 Zotikov AE, Teplov AA, Grickevich AA, Ivandaev AS. Extracorporeal surgery of kidneys and renal arteries. Moscow: Russkie vitjazi; 2019. pp. 128. 
15 Yoshida K, Kondo T, Takagi T, et al. Clinical outcomes of repeat partial nephrectomy compared to initial partial nephrectomy of a solitary kidney. Int J Clin Oncol. 2020;25(6):1155-62.

16 Master VA, Ethun CG, Kooby DA, Staley CA III, Maithel SK. The value of a cross-discipline teambased approach for resection of renal cell carcinoma with IVC tumour thrombus: A report of a large, contemporary, single institution experience. J Surg Oncol. 2018;1-8.

17 Kulisa M, Bensouda A, Vaziri N, et al. Tumeurs rénales complexes sur rein unique : résultats de la chirurgie partielle ex vivo avec autotransplantation [Complex renal tumors on solitary kidney: results of ex vivo nephron-sparing surgery with autotransplantation]. Prog Urol. 2010;20(3):194-203.

18 Abraham GP, Siddaiah AT, Ramaswami K, George D, Das K. Ex-vivo nephron-sparing surgery and autotransplantation for renal tumours: Revisited. Can Urol Assoc J. 2014;8(9-10):E728-32.

19 Bourgi A, Aoun R, Ayoub E, Moukarzel M. Experience with renal autotransplantation: Typical and atypical indications. Adv Urol. 2018;3:3404587. 